\title{
Production of Alumina from Local Clays using Nitric and Acetic Acids
}

\author{
Kenneth Kekpugile.Dagde* Nwankwo Chiedozie Onyebuchi \\ Department of Chemical and Petrochemical Engineering, Rivers State University, \\ Port Harcourt, Rivers State, Nigeria
}

\begin{abstract}
The study was carried out to investigate the effect of process variables on the production of alumina $\left(\mathrm{Al}_{2} \mathrm{O}_{3}\right)$ by leaching of local clays obtained from four different locations in Nigeria - Ikot-Abasi, Enito II, Akpugo and Awgbu containing $56.00 \%, 8.45 \%, 25.28 \%$ and $14.43 \%$ of $\mathrm{Al}_{2} \mathrm{O}_{3}$ respectively. The process variables whose effect on alumina leaching investigated were: acids concentration (2M to $10 \mathrm{M})$, calcinations temperature $\left(200^{\circ} \mathrm{C}\right.$ to $\left.1000^{\circ} \mathrm{C}\right)$, calcinations time (15 to 75 minutes), leaching time (20 to 100 minutes) and particles size ( 75 to $1000 \mu \mathrm{m}$ ) with the experiment conducted at constant boiling temperatures of the acids used (Nitric and Acetic acid). The recommended leaching conditions used as obtained from literature were: $6 \mathrm{M}$ for the two acids concentrations, particles size of $150 \mu \mathrm{m}$, calcinations and leaching time of one hour and calcinations temperature of $600^{\circ} \mathrm{C}$. Upon leaching of these clays under prescribed conditions, the optimal yield obtained by varying each of the process variables were noted. Calcination temperature was observed to have the highest effect on the yield of alumina extractible providing the highest yield of alumina after analysis using mass adsorption spectrophotometer. The yield of alumina presented under the variation of calcination temperature were: Ikot-Abasi clay and nitric acid yield of $68.10 \%$ alumina; Ikot-Abasi and Acetic - yield of $38.07 \%$ alumina; Enito II and nitric acid - yield of $56.50 \%$ alumina; Enito II clay and acetic acid - yield of $43.41 \%$ alumina; Awgbu clay and nitric acid - 59.04\% alumina yield; Awgbu clay and acetic acid - alumina yield of 46.55\%; Akpugo clay and nitric acid - alumina yield $53.47 \%$; Akpugo clay and acetic acid - alumina yield $43.23 \%$. It was observed that Ikot-Abasi clay/nitric acid gave the best yield.
\end{abstract}

Keywords: Local Clays, Alumina, Nitric Acid, Acetic Acid, Mass Adsorption Spectrophotometer.

DOI: $10.7176 / \mathrm{CPER} / 60-05$

Publication date:March $31^{\text {st }} 2019$

\section{Introduction}

In almost every part of the world, the major raw material for the manufacture of alumina has been industrial refinement of bauxite (Bayer process). Bauxite is known to contain 30-54\% of aluminum oxide. The quantity of bauxite available is limited compared to its demand industrially. For the sake of conservation of resources against the backdrop of extinction, it becomes only natural to look for other means of extracting alumina from other cheaper and readily available local raw materials containing significant amount of alumina. In recent times, local clays have been the focus of these experimental studies for alumina production in which clays from Nigeria and some parts of Saudi Arabia have come under investigation (Al-Zahrani and Abdul-Majid, 2009; Ajemba and Onukwuli, 2012).

Quite a number of processes have been investigated for production of alumina from kaolin and other types of clays - chiefly sintering, treatment of clays with acids or the continuous electrolysis of aluminum chloride (Austin, 1984). The French Pechiney-Ugine Kuhlmann process treats clays and shales with concentrated sulphuric acid. Hydrochloric acid is added during the crystallization step to form aluminium chloride which crystallizes readily (Barclay and Peters, 1976).

In the kingdom of Saudi Arabia, kaolinitic clay obtained from Riyadh area (N: 24 00'36", E: 47"44”03") was subjected to leaching using hydrochloric acid. The analysis of the aluminium ion present after leaching was carried out using the solar MS Atomic Absorption Spectrophotometer. The results of their experiment showed that $62.9 \%$ of alumina present in the local clay was extracted under optimum calcinations conditions of $600^{\circ} \mathrm{C}$ and 1 hour (Al-Zahrani and Abdul-Majid, 2009).

Ozdemir and Cetisli, 2015 studied the extraction kinetics of alunite in sulphuric acid and hydrochloric acid in a batch reactor. The effects of reaction temperature, acid concentration, particle size, calcinations temperature, and calcinations time and aci/ $\mathrm{Al}_{2} \mathrm{O}_{3}$ molar ratio on the extraction process were investigated. The calcinations temperature was found to be the most important parameter affecting the extraction process followed by the reaction temperature.

Ajemba and Onukwuli, 2012 studied the effects of hydrochloric acid-leaching on the structural and adsorptive performance of Nteje clay in Nigeria. In their analysis, it was observed that hydrochloric acid leaching caused an exchange of $\mathrm{Al}^{3+}, \mathrm{Fe}^{3+}$ and $\mathrm{Mg}^{2+}$ with $\mathrm{H}^{+}$ions which led to a modification in the clay crystalline structure and caused an increase in the adsorptive capacity of the clay from $35.7 \%$ (raw clay sample) to $88.9 \%$ (leached sample with $3 \mathrm{M} \mathrm{HCl}$ ). 
A different work was carried out by the same authors on the optimization of extracting alumina from the same clay (Nteje clay) using sulphuric acid. Response surface methodology was employed to optimize the sulphuric acid leaching of alumina from the clay based on the central composite rotatable design. Following this, a model was developed with the adequacy tested using the sequential model sum of squares. The optimum conditions generated for the process parameters showed that $81.87 \%$ was extractible.

In another recent development, the kinetic study of hydrochloric acid leaching of alumina from Agbaja clay (Kogi State, Nigeria) was investigated. It was observed that obtaining alumina from the clay was seriously hindered due to small surface area and presence of negative surface charges but by improved thermal activation and effects of most other process variables excluding particle size the yield substantially increased. A kinetic equation and optimal conditions was developed with activation energy calculated as $34 \mathrm{KJ} / \mathrm{mol}$ (Uchenna et al, 2015).

It was reported in literature that some of the more important advantages of using hydrochloric acid over other acids for leaching of alumina were the ease of filtration of slurries, the ease of iron removal and the insolubility of titanium dioxide, which is present in many clays. The most seri*ous problem connected with the use of hydrochloric acid was severe corrosion; however, the development of corrosion resistant plastics and rubbers partially solved this problem so that corrosion is no longer a prohibitive factor (Peters et al, 1962). Hydrochloric, sulphuric and nitric acids extract approximately the same quantity of alumina from each ton of clay (Sharp, 1949).

In the present study, the alumina content contain in Nigeria clays from four different locations - Ikot-Abasi in Akwa Ibom State, Enito II in Rivers State, Awgbu in Anambra State and Akpugo in Enugu State were investigated. The use of nitric and acetic acids as leaching media provided an exciting study on how these two acids could generate different yields as a deviant from other researchers who used hydrochloric acid as the only leaching medium. The results obtained can serve also as a basis of comparison with works on clays in close geographical areas of the South-South and South-East of Nigeria).

\section{Materials and Methods \\ 2.1 Materials}

The following materials were used: Distilled water, Drying oven, Measuring cylinder, Electronic weighing balance, Beakers, Conical flasks, Stop watch/clock, Stirrer (glass), Crusher, Sledge hammer, Teflon crucibles, Tubes with covers, Masking tape, Hand gloves, Nose masks, Sieves and trays, Spectrophotometer, Nitric acid, Acetic acid

\subsubsection{Source of Local Clays}

The clay samples were obtained from Ikot-Abasi (Okon community) in Akwa Ibom State, Enito II (Enito II community) in Rivers State, Awgbu (Ogwu community) in Anambra State and Akpugo (Ogbozinne community) in Enugu State, South-South and South-East of Nigeria.

\subsection{Methods}

\subsubsection{Preparation of the Clays}

The clay samples were washed with distilled water to remove surface dirt and other forms of impurities and then dried under the sun for 24 hours. The washed samples were dried in an oven at $100^{\circ} \mathrm{C}$ for 12 hours. The hardened clay was ground/crushed and sieved to the required particle sizes.*

\subsubsection{Acid Preparation}

Required molar concentrations of the acid were: $2 \mathrm{M}, 4 \mathrm{M}, 6 \mathrm{M}, 8 \mathrm{M}$ and $10 \mathrm{M}$.

To prepare a $1 \mathrm{M}$ concentration:

$V_{x}=\frac{M W \times 100}{S G \times \% \text { assay }}$

where, $\mathrm{V}_{\mathrm{x}}=$ volume of acid to be measured out, $\mathrm{SG}=$ specific gravity, $\mathrm{MW}=$ molecular weight of the acid 2.2.3 Characterization of clay samples

This was carried out to determine the chemical composition of each of the clay sample used. After washing and drying of the clay sample to remove dirt. 3 grams of each sample was collected in a platinum crucible and analysed for its physio-chemical properties.

\subsubsection{Determination of $\mathrm{Al}_{2} \mathrm{O}_{3}$}

$3 \mathrm{~g}$ of the sample (clay) was weighed into a beaker. $100 \mathrm{ml}$ of water added to th*e sample. The solution was then boiled on a hot plate and $1 \mathrm{ml}$ of $1 \%$ phenolphthalein indicator added. While the solution was still boiling, it was then titrated with $0.5 \mathrm{~N} \mathrm{NaOH}$ solution. The solution was stirred continuously until a permanent pink colour was obtained signifying the end point.

$\% \mathrm{Al}_{2} \mathrm{O}_{3}=\frac{T_{V}}{\text { Weight taken }} \times 100$

where $T_{V}=$ Titre value

\subsubsection{Determination of $\mathrm{SiO}_{2}$}

$3 \mathrm{~g}$ of the sample was put in a platinum crucible. The sample was taken into a furnace, ignited to about $800^{\circ} \mathrm{C}$ and then treated with hydrofluoric acid. The sample was taken out of the furnace and re-weighed to record the weight 
lost. The silicate evolved as silicon tetra-fluoride and was calculated thus:

$\%$ Silicate $=\frac{\text { weight of silicate (residue) }}{\text { weight of initial sample used }} \times 100$

\subsubsection{Determination of $\mathrm{CaO}$}

$3 \mathrm{~g}$ of weighed sample was added into a beaker and diluted with about $100 \mathrm{ml}$ of distilled water. The mixture was warmed using a hot plate. A reference end point was obtained by mixing $5 \mathrm{ml}$ of $\mathrm{NaOH}$ with the indicator (Murexide - ammonum purpurate) and diluted with $100 \mathrm{ml}$ of water. In another titration flask, the sample was titrated with $0.5 \mathrm{~N} \mathrm{NaOH}$ and EDTA (di-sodium salt of ethylenediaminetetra-acetic acid) solution until the colour matched the referenced end point.

$\% C a O=\frac{T_{V} \text { of EDTA }}{\text { Weight taken }} \times 100$

\subsubsection{Determination of $\mathrm{Fe}_{2} \mathrm{O}_{3}$}

$3 \mathrm{~g}$ of clay sample diluted with $100 \mathrm{ml}$ of distilled water was put in a beaker, $40 \mathrm{ml}$ of $0.3 \mathrm{M} \mathrm{Na}$-citrate solution and $5 \mathrm{ml}$ of $1 \mathrm{M} \mathrm{NaHCO}_{3}$ solution was added to it. The temperature was raised to $80^{\circ} \mathrm{C}$ using a water bath before the addition of $1 \mathrm{~g}$ of solid $\mathrm{Na}_{2} \mathrm{SO}_{4}$. The mixture was stirred continuously for 15 minutes. At the end of 15 minutes, $10 \mathrm{ml}$ of $\mathrm{NaCl}$ solution together with $10 \mathrm{ml}$ of acetone was added to promote flocculation. The suspension was then mixed, warmed in a water bath, poured into a tube and centrifuged for $5 \mathrm{~min}$ at $1600-2200 \mathrm{rev} / \mathrm{min}$. The clear part of the suspension (supernatant) was decanted into another beaker. The sample was then taken to the MS Atomic Absorption Spectrophotometer for analysis of Iron oxide content.

\subsubsection{Calcination of Clay Sample}

The clay samples of various sizes were heated for thermal activation. The calcination temperatures required for the process were: $200,400,600,800,1000^{\circ} \mathrm{C}$ at calcination times of $15,30,45,60,75$ minutes. The calcination time was the period when the clay samples were left in the oven at specified temperatures.

2.2.9 Measurement of Alumina Properties

Density: Dried alumina powder was weighed in a crucible after the mass of the crucible had been obtained. $30 \mathrm{ml}$ of water was poured into a graduated cylinder. The weighed alumina was then added into the cylinder and the volume recorded as the displaced amount of water from initial reading. Density was then calculated as:

$$
\text { Density, } \rho=\frac{\text { mass }}{\text { volume }}
$$

\section{Thermal Conductivity}

The guarded hot plate was used for this experiment. Alumina sample in a crucible was placed between two plates. One plate was heated up and the other cooled and their temperatures monitored until they became constant and were recorded. The heat input to the hot plate was recorded, and the distance between these two plates were also noted. Thermal conductivity then calculated

$$
\text { Thermal Conductivity, } \lambda=\frac{q \times d(W / m)}{T_{1}-T_{2}(K)}
$$

where $\mathrm{q}$ is the quantity of heat supplied per unit area $\frac{W}{m^{2}}, \mathrm{~d}$ is the distance between the two plates (m), $\mathrm{T}_{1}$ is the temperature of the hot plate $(\mathrm{K})$ and $\mathrm{T}_{2}$ is the temperature of the cold plate $(\mathrm{K})$

q was calculated as $\frac{Q(W)}{A\left(m^{2}\right)}$

where $\mathrm{Q}$ is the heat supplied to the hot plate $(\mathrm{W}), \mathrm{A}$ is the base area of the hot plate $\left(\mathrm{m}^{2}\right)$

\section{Determination of Specific Heat Capacity}

A copper calorimeter was used for this experiment. $5 \mathrm{~g}$ of dried alumina was put in a crucible and heated to $100^{\circ} \mathrm{C}$. Measured amount of cold water was poured in a calorimeter to quarter full. The temperature of this cold water is taken and noted down which is same as temperature of calorimeter. The heated alumina at $100^{\circ} \mathrm{C}$ is then poured in to the water in the calorimeter and then stirred until uniform temperature is attained. The specific heat capacity of alumina is thus calculated as:

$$
m_{a} c_{a} \Delta T_{a}=m_{c} c_{c} \Delta T_{c}+m_{w} c_{w} \Delta T_{w}
$$

where $m_{a}, m_{c}, m_{w}$ the masses of alumina are, copper and water respectively $(\mathrm{g})$

$c_{a}, c_{c}, c_{w}$ are the specific heats of alumina, copper and water respectively. Those of copper and water are known $\left(0.385 \mathrm{~J} / \mathrm{g} \mathrm{K}\right.$ and $4.184 \mathrm{~J} / \mathrm{g} \mathrm{K}$ respectively), $\Delta T_{a}$ is the fall in the temperature of alumina from $100^{\circ} \mathrm{C}$ to final temperature $(\mathrm{K}), \Delta T_{c}$ is the rise in the temperature of the calorimeter from initial to final temperature $(\mathrm{K}), \Delta T_{w}$ is the rise in the temperature of the water from initial to final temperature $(\mathrm{K})$

\subsubsection{Leaching experiment}

$$
\Delta T_{c}=\Delta T_{w}
$$

Before leaching, the washed and dried clay samples were ground and sieved into various particle sizes between $75 \mu \mathrm{m}$ and $1000 \mu \mathrm{m}$ and labelled accordingly. These sized fractions were then heated in a furnace between the temperature ranges of $200^{\circ} \mathrm{C}$ to $1000^{\circ} \mathrm{C}$ at different times ranging from 15 minutes to 75 minutes. For each leaching experiment, $10 \mathrm{~g}$ of each fraction was weighed out and reacted with already prepared acid concentrations ranging 
from $2 \mathrm{M}$ to $10 \mathrm{M}$ and time of leaching varied between 20 minutes to 100 minutes. The experiment was conducted at isothermal conditions using the boiling temperature of the acids. By continuous stirring of the mixture, uniformity was ensured. After the reaction time was completed, the suspension was immediately filtered to separate undissolved materials and the filtrates anlayzed for aluminum ion using the MS Atomic Absorption Spectrophotometer. The process variables investigated were: Leaching time $\left(\mathbf{X}_{1}\right)-20,40,60,80,100$ minutes, Calcination temperature $\left(\mathbf{X}_{2}\right)-200,400,600,800,1000^{\circ} \mathrm{C}$, Calcination time $\left(\mathbf{X}_{3}\right)-15,30,45,60,75$ minutes, Acid concentration $\left(\mathbf{X}_{4}\right)-2 \mathrm{M}, 4 \mathrm{M}, 6 \mathrm{M}, 8 \mathrm{M}, 10 \mathrm{M}$, Particle Size $\left(\mathbf{X}_{\mathbf{5}}\right)-75,150,300,850,1000 \mu \mathrm{m}$ at acid to clay weight ratio of 10:1. The constant values of the variables used while varying the variable of interest were Calcination temperature: $600^{\circ} \mathrm{C}$, Calcination Time: 1 hour, Leaching time: 80 minutes, Acid concentration: $6 \mathrm{M}$ and Particle size: $150 \mu \mathrm{m}$. These gave the optimal values as compared with literature.

\section{Results and Discussion}

3.1 Characterization of Clays Table 1: Chemical Composition of Ikot-Abasi, Enito II, Akpugo and Awgbu Clays

\begin{tabular}{ccccc}
\hline Chemical Components & $\begin{array}{c}\text { Ikot-Abasi } \\
\text { Composition (\%) }\end{array}$ & $\begin{array}{c}\text { Enito II } \\
\text { Composition } \\
\text { (\%) }\end{array}$ & $\begin{array}{c}\text { Akpugo } \\
\text { Composition } \\
\text { (\%) }\end{array}$ & $\begin{array}{c}\text { Awgbu } \\
\text { Composition } \\
\mathbf{( \% )}\end{array}$ \\
\hline $\mathrm{SiO}_{2}$ & 25.29 & 44.01 & 44.35 & 51.00 \\
$\mathrm{Al}_{2} \mathrm{O}_{3}$ & 56.00 & 8.45 & 25.28 & 14.43 \\
$\mathrm{CaO}$ & 0.88 & 0.64 & 0.14 & 0.50 \\
$\mathrm{Fe}_{2} \mathrm{O}_{3}$ & 1.17 & 2.08 & 3.24 & 1.58 \\
$\mathrm{Na}_{2} \mathrm{O}$ & 0.56 & 1.04 & 4.68 & 0.33 \\
$\mathrm{~K}_{2} \mathrm{O}$ & 3.32 & 6.73 & 4.68 & 0.90 \\
\hline
\end{tabular}

Table 1 shows the chemical composition of clays obtained from Ikot-Abasi, Enito II, Akpugo and Awgbu respectively. The alumina $\left(\mathrm{Al}_{2} \mathrm{O}_{3}\right)$ compositions were $56.00 \%, 8.45 \%, 25.28 \%$ and $14.43 \%$ for the Ikot-Abasi, Enito II, Akpugo and Awgbu clays respectively. It was evident that the Ikot-Abasi clay had the highest chemical composition of $56.00 \%$ with the least of $8.45 \%$ from Enito II clay. This implied that a greater amount of alumina should be available for extraction in the Ikot-Abasi clay as compared to others used in this study.

\subsubsection{Physical Properties}

Table 2: Comparison of Properties of Extracted Alumina with literature values

\begin{tabular}{|c|c|c|c|c|c|c|}
\hline Property & Units & Ikot-Abasi & Enito II & Akpugo & Awgbu & $\begin{array}{l}\text { Literature: } \\
\text { Auerkari(1996) } \\
\text { and } \\
\text { Patnaik(2002) }\end{array}$ \\
\hline Odour & - & Odourless & Odourless & Odourless & Odourless & Odourless \\
\hline Molar Mass & $\mathrm{g} / \mathrm{mol}$ & 101.96 & 101.96 & 101.96 & 101.96 & 101.96 \\
\hline Density & $\mathrm{g} / \mathrm{cm}^{3}$ & 3.970 & 3.800 & 3.780 & 3.910 & $3.75-3.99$ \\
\hline Melting Point & $\mathrm{K}$ & 2326 & 2269 & 2308 & 2291 & $2277-2369$ \\
\hline $\begin{array}{l}\text { Thermal } \\
\text { Conductivity }\end{array}$ & $\mathrm{W} / \mathrm{mK}$ & 25.1 & 22.4 & 14.9 & 30.5 & $12.0-38.5$ \\
\hline Specific Heat & $\mathrm{J} / \mathrm{gK}$ & 0.888 & 0.682 & 0.882 & 0.906 & $0.45-0.955$ \\
\hline
\end{tabular}

Table 2 depicts the physical properties of alumina extract. Comparing values of the properties from the analysis with standard obtained from literature, it could be seen that the extracted alumina possessed qualities in close agreement with standard.

\subsection{Leaching Experiments}

3.2.1 Acid Concentration

The effect of acid concentrations on the extraction of alumina is illustrated in Figures 1 to 4 . 


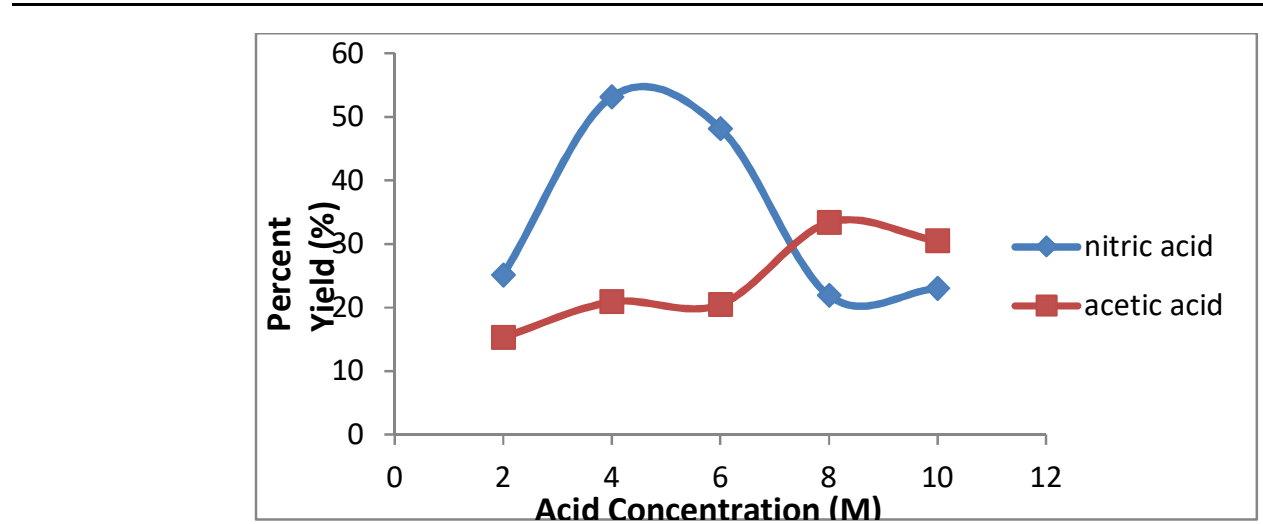

Figure 1: Percent Yield of Alumina versus Acid Concentration for Ikot-Abasi Clay

In Figure 1, the effect of the acids used on Ikot-Abasi clay showed two different behavioural plots. The optimal yield obtained using nitric acid was observed to be at $4 \mathrm{M}$ acid concentration while that using acetic acid at $8 \mathrm{M}$. This could be explained by looking closely at the property of nitric acid where in its dilute state, it is almost completely ionized into its ions and thus acted as a strong acid. As its concentration increased, it became poorly ionized. On the other hand, increasing the concentration of acetic acid led to better extraction until at an optimal concentrations of $8 \mathrm{M}$ where further increased in acid concentrations resulted in no significant change in the yield. More so, the yield obtained using nitric acid was observed to be much more than that of acetic acid. This could probably due to nitric acid being a stronger acid than acetic acid, and therefore possessed better extraction ability. Maximum alumina extraction using nitric acid was $53.17 \%$ while that obtained using acetic acid was $33.38 \%$.

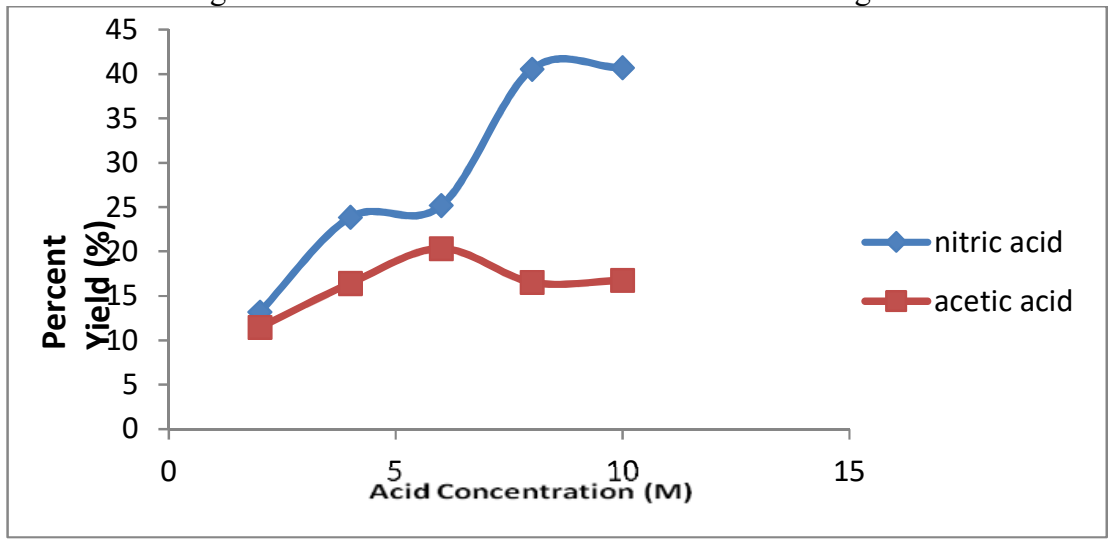

Figure 2: Percent Yield of Alumina versus Acid Concentration for Enito II Clay

In Figure 2, it was seen that the yield of alumina increased significantly with nitric acid as the leaching agent until at $8 \mathrm{M}$ where a further increase in the acid concentration caused an insignificant increase in yield of alumina. It was also noticed that after $4 \mathrm{M}$ the change in yield on further increased in acid concentrations was almost insignificant after which there was a rapid increased in the yield obtained. This rapid increase could be due to the oxidizing power of the acid being predominant at this stage, hence enhancing extraction via conversion of aluminum ions $\left(\mathrm{Al}^{3+}\right)$ to alumina $\left(\mathrm{Al}_{2} \mathrm{O}_{3}\right)$. Using acetic acid as the leaching agent, it was observed that after $6 \mathrm{M}$ acid concentration, there was a corresponding decreased in the yields. An explanation to this decreased might be due to increased presence of $\mathrm{Al}^{3+}$ ions blocking the diffusion of the $\mathrm{H}^{+}$ions of the acid. 


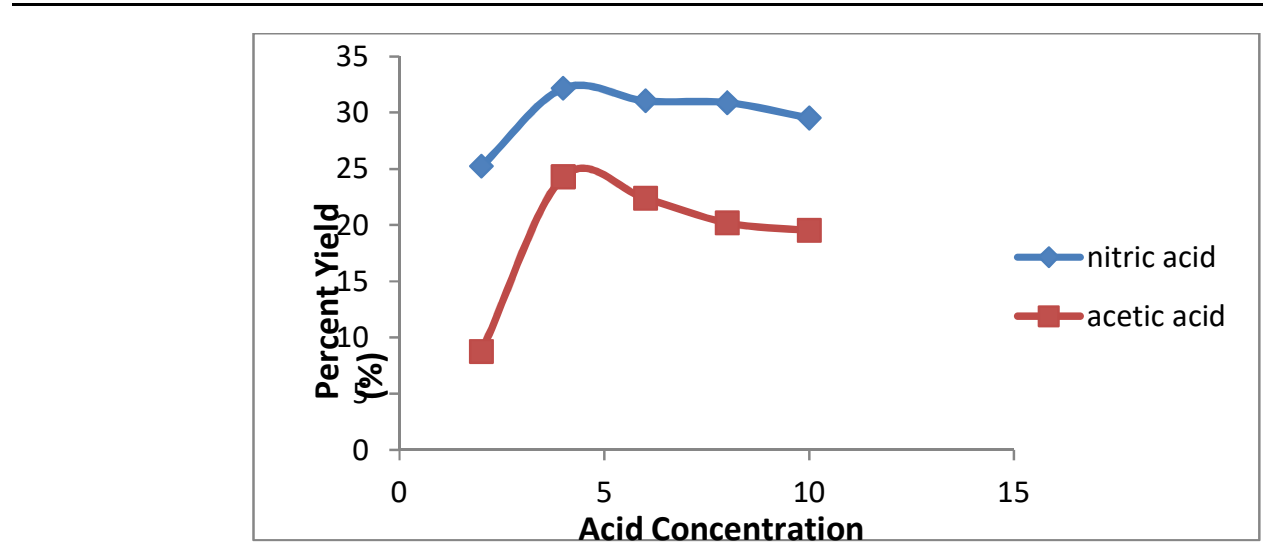

Figure 3: Percent Yield of Alumina versus Acid Concentration for Awgbu Clay

The effect of acid concentrations on the extraction of alumina from Awgbu clay could be observed from Figure 3. It was observed that using both acids, the highest yield of extract was at $4 \mathrm{M}$ concentrations of each acid. Further increase resulted in slow decreased of the yield. This decreased in yield following increasing acid concentration could be attributed to the same reason as explained earlier for Enito II clay. Maximum alumina extraction using nitric acid was $32.16 \%$ while that obtained using acetic acid was $24.31 \%$.

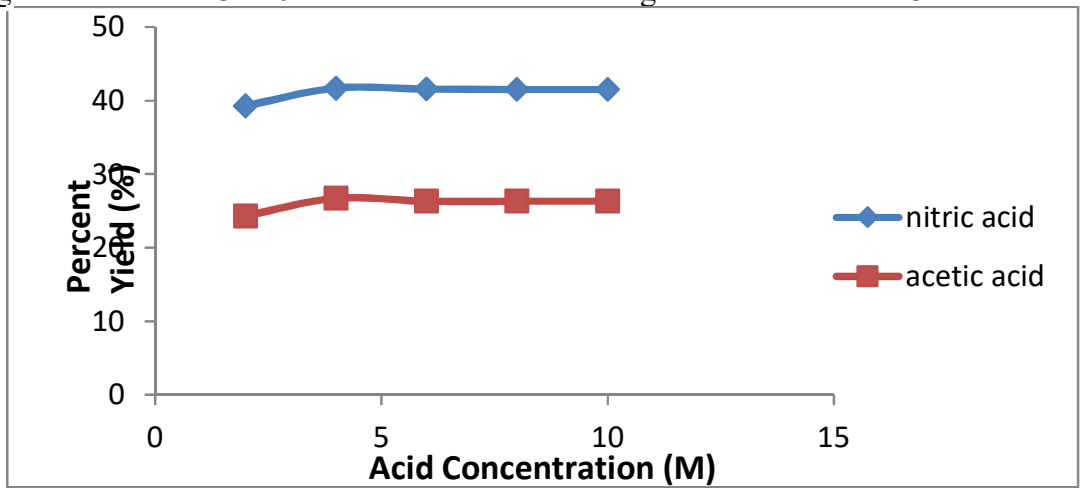

Figure 4: Percent Yield of Alumina versus Acid Concentration for Akpugo Clay

A similar profile was observed for Awgbu clay when acid concentrations was varied for Akpugo clay as seen in Figure 4. The optimal yield was obtained at $4 \mathrm{M}$ acid concentrations after which there was a steady decline in the yield of alumina. The quantity of alumina extracted from Akpugo clay was also observed to be higher than that of Awgbu clay, possibly due to the higher alumina content in the former. Maximum alumina yields observed using nitric acid was $41.70 \%$ while that of acetic acid was $26.73 \%$.

\subsection{Leaching Time}

Figures 5 to 8 and 13 to 16 depict the effect of time variables on the yields of alumina. While Figures 5 to 8 represents the effect of reaction time, Figures 13 to 16 represents the effect of activation time.

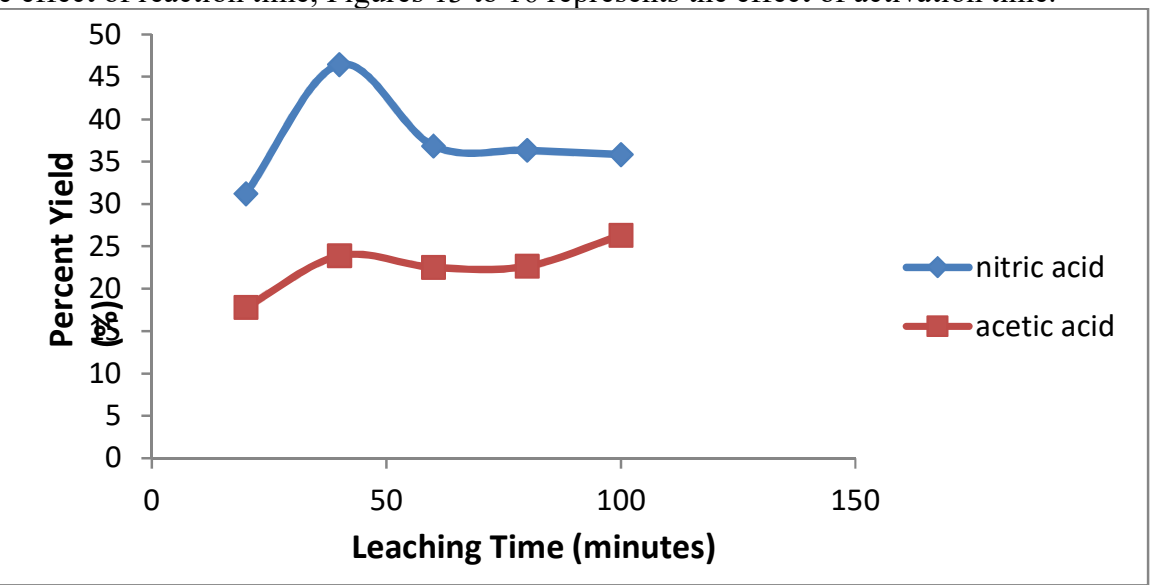

Figure 5: Percent Yield of Alumina versus Leaching Time for Ikot-Abasi Clay 
Figure 5 shows that increased in reaction time led to increase in the yields of alumina using nitric acid until after 40 minutes where there was sharp decreased and subsequent insignificant changed. This might be probably due to the alumina so formed dissociating again into its ions after 40 minutes (reversible reactions) and subsequently stabilizing with increased time. Using acetic acid, it was observed that the yields increased up to the 100 minutes. It was predicted that higher yields could be obtained if the reactions time was increased even further.

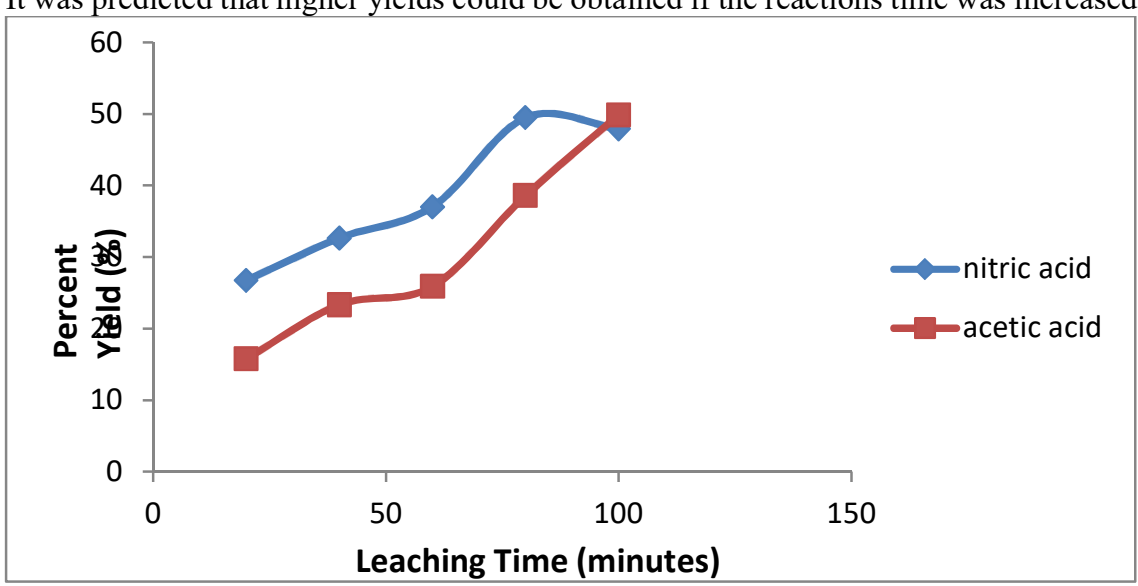

Figure 6: Percent Yield of Alumina versus Leaching Time for Enito II Clay

For Enito II clay, the optimal leaching time using nitric acid was 80 minutes as seen from Figure 6 while a continual increased was observed using acetic acid.

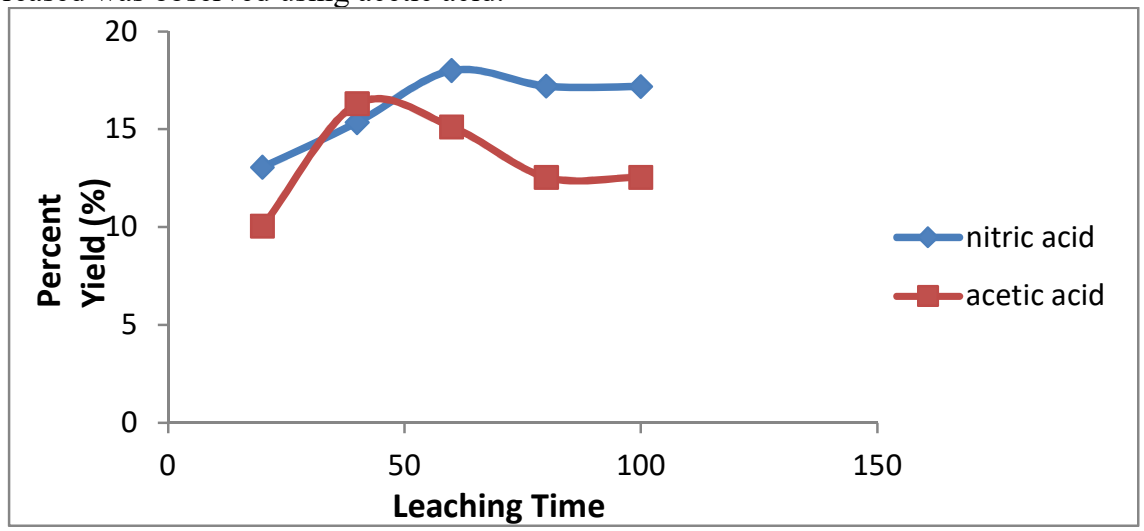

Figure 7: Percent Yield of Alumina versus Leaching Time for Awgbu Clay

Figure 7 shows the effects of leaching time on the yields of alumina for Awgbu clay. Using nitric acid, the optimum yields was observed at 60 minutes while using acetic acid was 40 minutes. This time variance for acetic acid might be due to the kaolin structure of the Awgbu clay collapsing after 40 minutes.

At 80 minutes, nitric acid leaching resulted to $18.00 \%$ alumina extracts and acetic acid leaching resulted to $16.30 \%$ extracts.

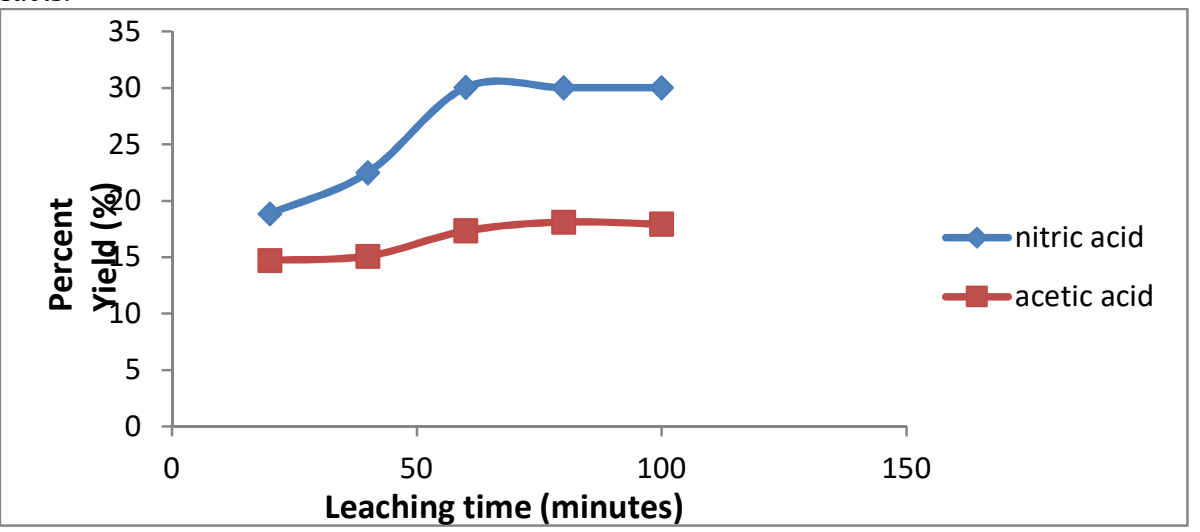

Figure 8: Percent Yield of Alumina versus Leaching Time for Akpugo Clay 
As shown in Figure 8, A similar trend was observed for Akpugo clay. However, there were similarities in the behavior of the two acids as both gave optimal alumina yield at 60 minutes. Beyond this point, it could be safe to say that further increase in reaction time resulted in no significant change in alumina yields.

\subsection{Calcination Temperature}

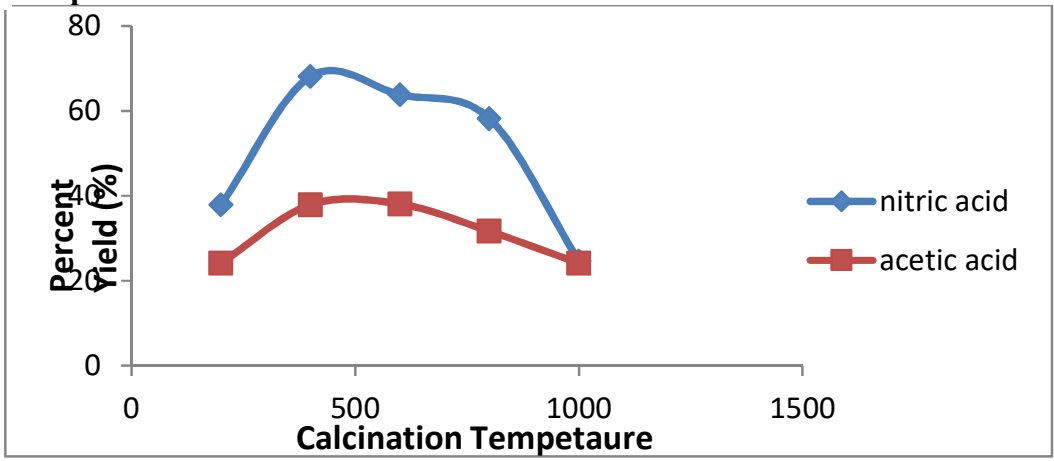

Figure 9: Percent Yield of Alumina versus Calcinations Temperature Ikot-Abasi Clay

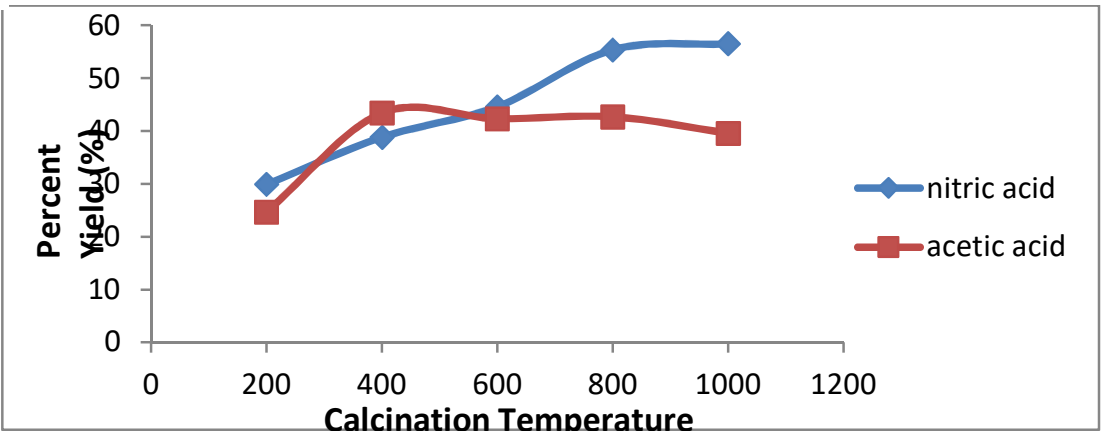

Figure 10: Percent Yield of Alumina versus Calcinations Temperature for Enito II Clay

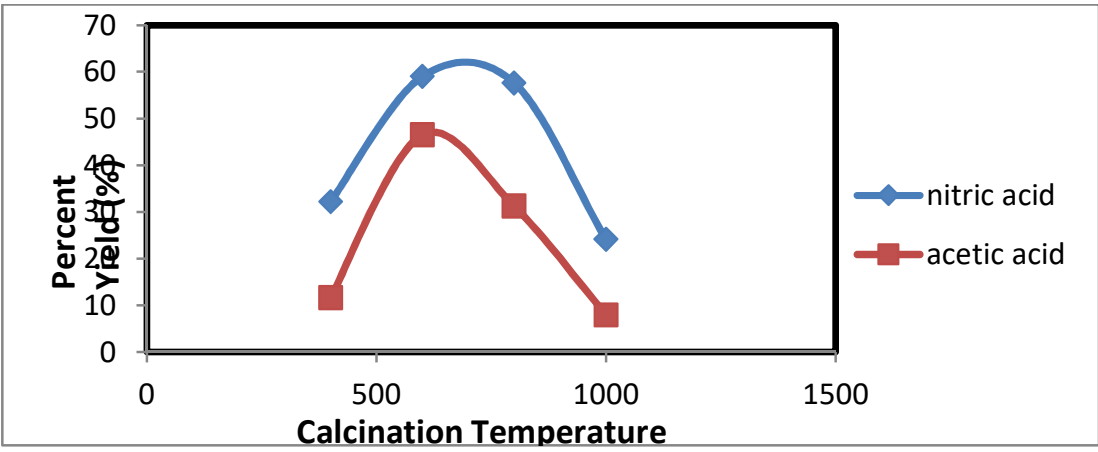

Figure 11: Percent Yield of Alumina versus Calcinations Temperature for Awgbu Clay 


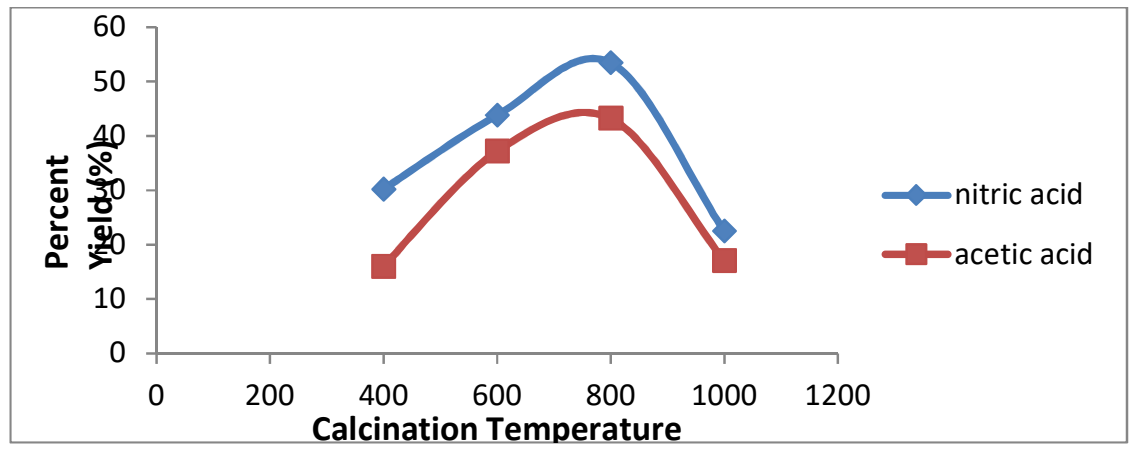

Figure 12: Percent Yield of Alumina versus Calcinations Temperature for Akpugo Clay

Figures 9 to 12 represent the effect of calcinations temperature on Ikot-Abasi, Enito II, Awgbu and Akpugo clays respectively. On close observation of all the experiments performed, calcinations temperature appeared to be the most important factor that affected alumina extractions. It was well known that increasing the temperature of the clay samples increased the number of active sites available for reaction thus resulting to improved alumina yield. The greatest yield of alumina obtained from the clays was at calcinations temperatures of $400^{\circ} \mathrm{C}$ to $800^{\circ} \mathrm{C}$. The decreased in alumina yield observed beyond these temperatures may be attributed to a total dehydration of the clay samples at this point where they became a very solid cake and also to the solid phase transformation of alumina beyond these temperatures.

\subsection{Period of Calcination}

Heating up the clay samples to increase the number of active sites in the clay for reaction very much goes with how long it is kept in the furnace. Keeping the clay in the furnace a little longer increases the amount of these active sites available in the clay sample.

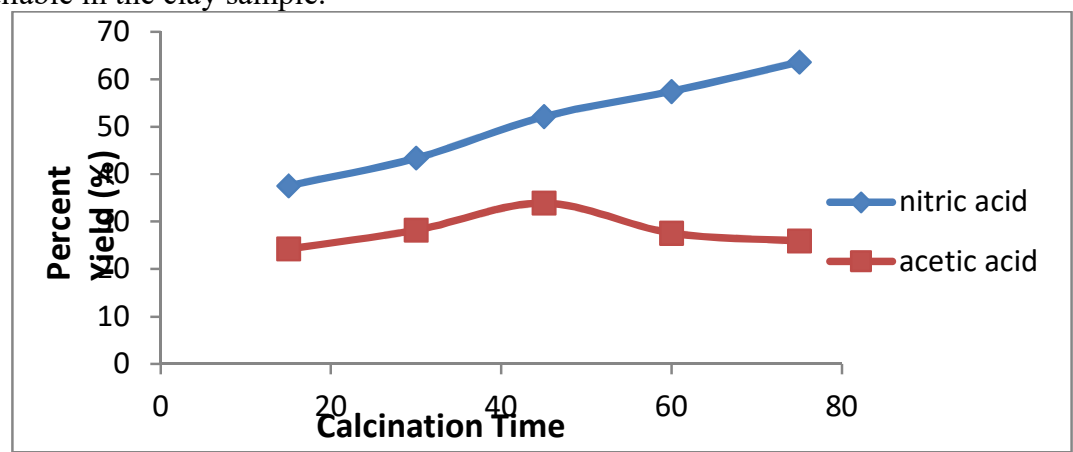

Figure 13: Percent Yield of Alumina versus Calcinations Time for Ikot-Abasi Clay

Figure 13 shows the effect of calcinations period on Ikot-Abasi clay. It was observed that using nitric acid, the percent yield kept increasing even after 60 minutes, while using acetic acid, maximum yield was obtained at 45 minutes. The slight decrease after 45 minutes might be due to any of the reasons given before. For Enito II clay, there was a progressive increased in the yield using both acids with increased period of calcinations. This is shown in Figure 14.

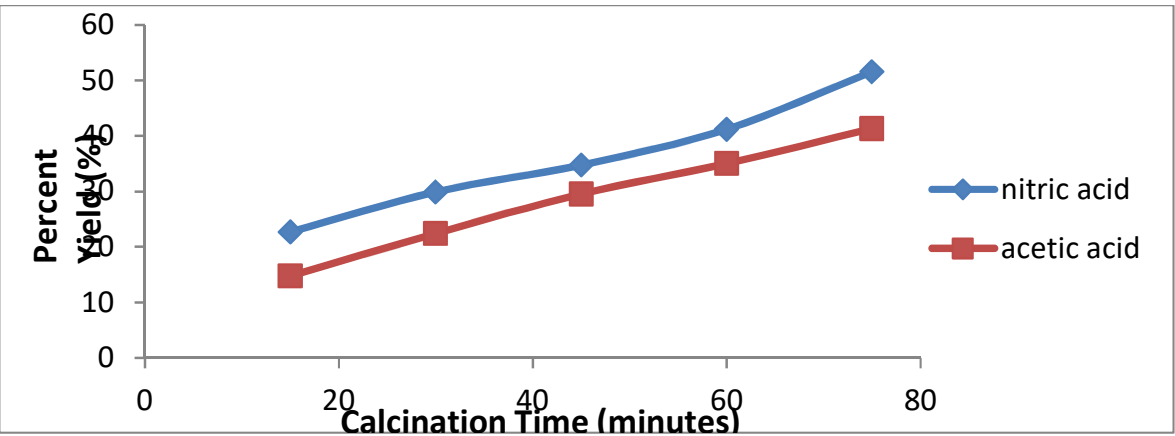

Figure 14: Percent Yield of Alumina versus Calcinations Time for Enito II Clay 


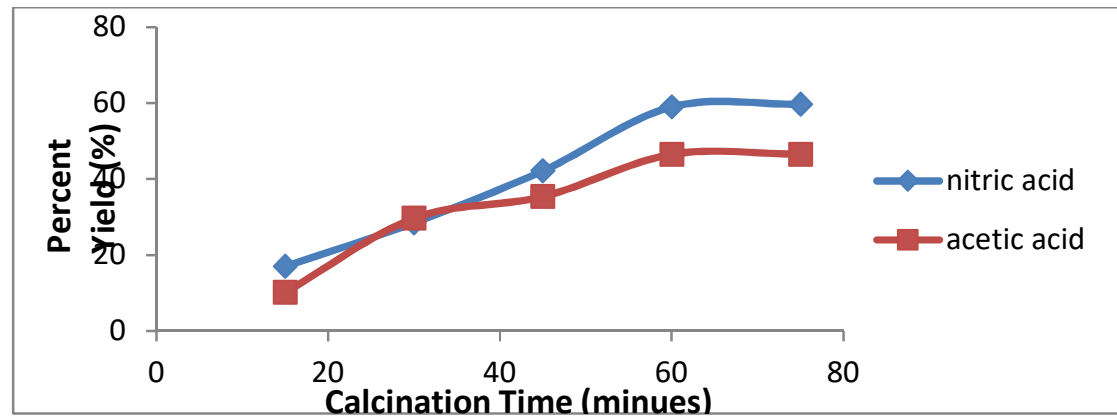

Figure 15: Percent Yield of Alumina versus Calcinations Time for Awgbu Clay

In Figure 15, it was observed that after 60 minutes, there was no more significant change in the yield obtained using both acids. This should represent the period at which the maximum amount of alumina available in the clay for extraction had been exhausted.

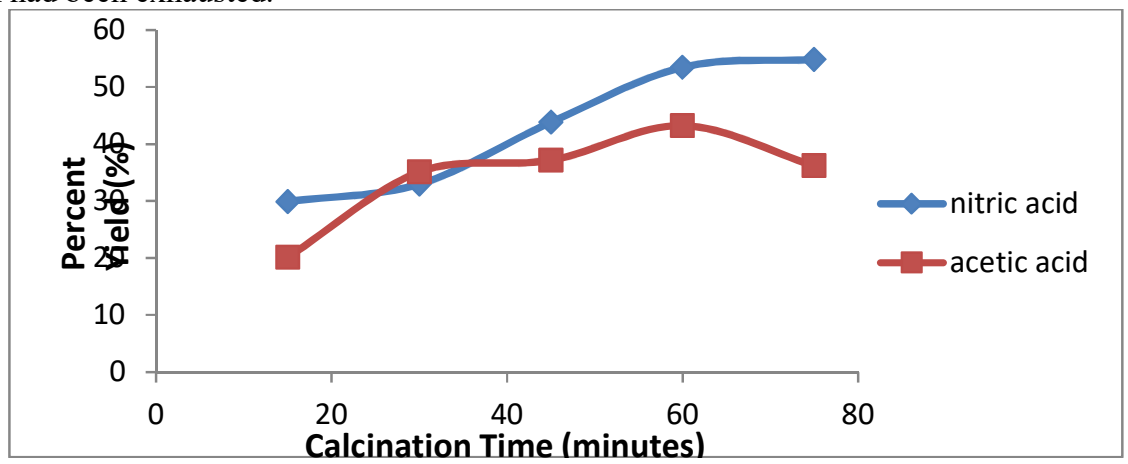

Figure 16: Percent Yield of Alumina versus Calcinations Time for Akpugo Clay

Figure 16 shows the effect of calcinations period on Akpugo clay. At 30 and 45minutes, the yields for both acids were the same as $35 \%$ and $37 \%$. The yields for acetic acid decreased apparently after 60 minutes.

\subsection{Particle Size}

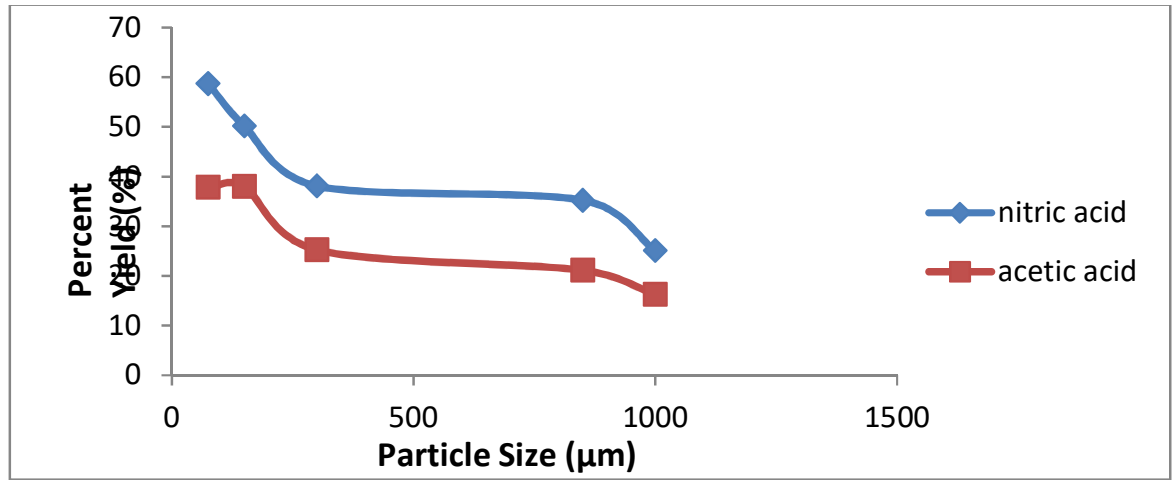

Figure 17: Percent Yield of Alumina versus Particle Size for Ikot-Abasi Clay

The effect of particle size on alumina yield for Ikot-Abasi clay is shown in Figure 17. Generally, the trend follows a gradual decrease in yield as the particle size of the clay sample increased. As the particle size increased, the specific area of the clay sample available for adsorption decreased, resulting in a continual decrease in the yield of alumina obtained. Between 75 and $150 \mu \mathrm{m}$ for the same clay using acetic acid, there seemed to be no change in the yield of alumina meaning that beyond $150 \mu \mathrm{m}$, the effect of decreasing particle size on yield of alumina became insignificant when Ikot-Abasi clay was leached with acetic acid. 


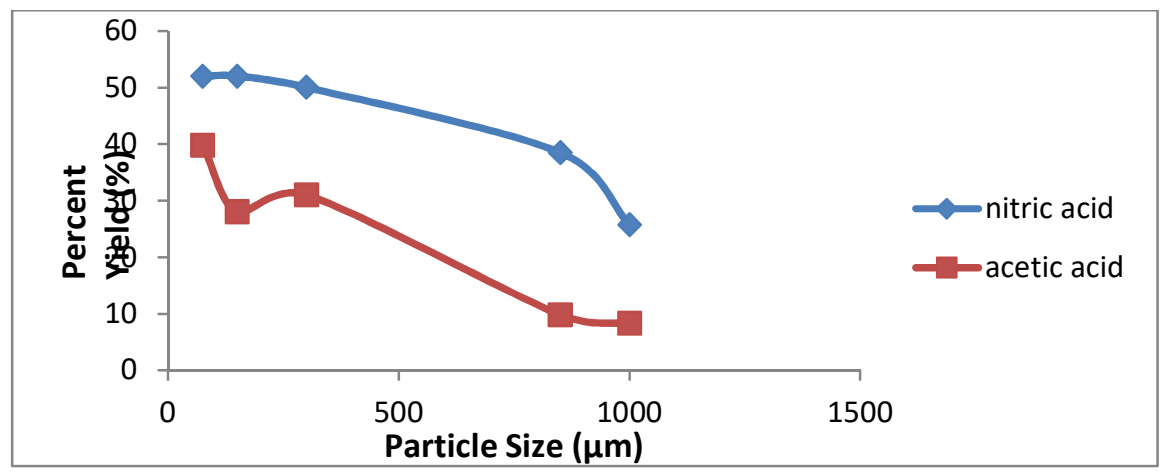

Figure 18: Percent Yield of Alumina versus Particle Size for Enito II Clay

A similar profile to the Ikot-Abasi clay was observed for Enito II clay as seen from Figure 18. Using acetic acid, between 150 and $300 \mu \mathrm{m}$, there appeared to be a slight increased in the yield on increasing the particle size a deviation from the general principle. This may probably be due to wrong readings obtained from the mass adsorption spectrophotometer for either of this clay sizes. Moreover, beyond $150 \mu \mathrm{m}$ using nitric acid, there was no significant change in the yield of alumina obtained compared to the other size ranges. Using acetic acid as the leaching agent, it was seen that there was a progressive decrease in the yield, as the particle size was increased. It was predicted that decreasing the particle size to beyond $75 \mu \mathrm{m}$ using acetic acid could even produce more yields of alumina.

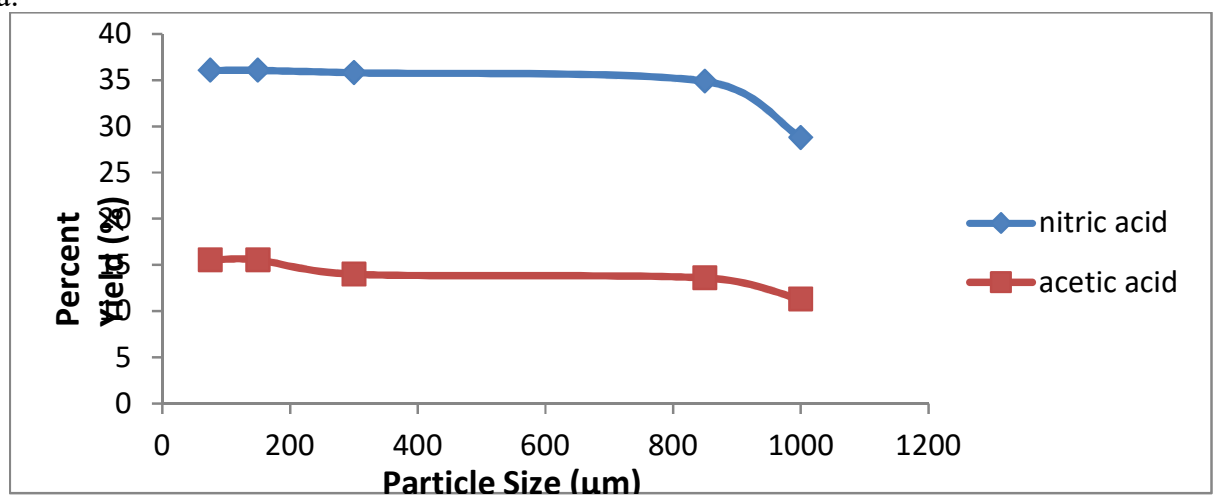

Figure 19: Percent Yield of Alumina versus Particle Size for Awgbu Clay

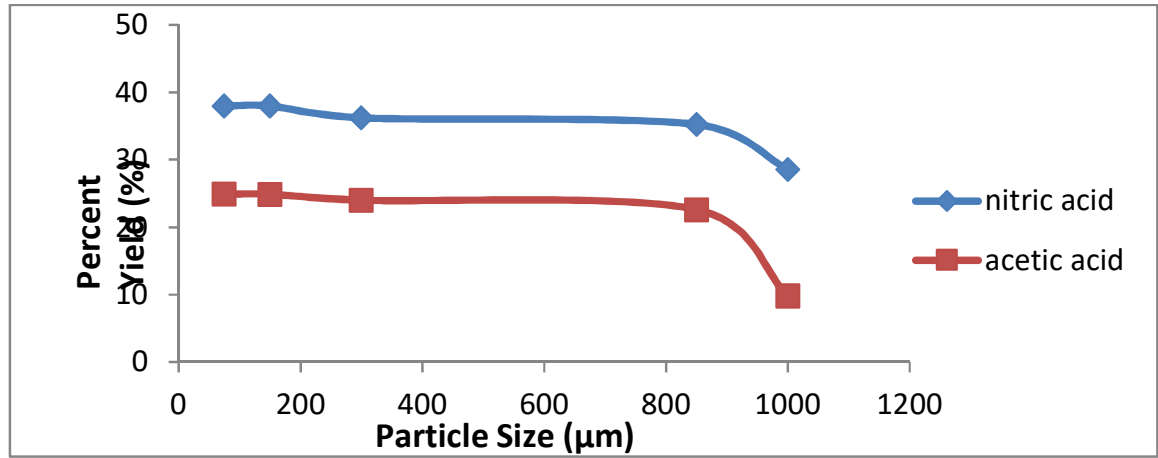

Figure 20: Percent Yield of Alumina versus Particle Size for Akpugo Clay

Figures 19 and 20 represent the effects of varying particle size of clay samples on alumina yield for Awgbu and Akpugo clay respectively. The same trend as with other clays was observed. It was also noted that decreasing the particle size beyond $150 \mu \mathrm{m}$ gave no significant change in the yields of alumina. Generally, as observed from all the experiments performed, calcinations temperature appeared to be the most significant factor that affect alumina extraction. The optimum yields of alumina obtained from the clay was at calcination temperatures of $400^{\circ} \mathrm{C}$ and $800^{\circ} \mathrm{C}$. The decreased in alumina yield beyond these temperatures may be attributed to a total dehydration of the clay samples where they became a very solid cake and to the solid phase transformation of alumina beyond these temperatures to $\alpha-\mathrm{Al}_{2} \mathrm{O}_{3}$ (the most thermodynamically stable phase of alumina). As the 
calcination temperature increased, the series of transformation was $\gamma-\mathrm{Al}_{2} \mathrm{O}_{3}-\delta-\mathrm{Al}_{2} \mathrm{O}_{3}-\theta-\mathrm{Al}_{2} \mathrm{O}_{3}-\alpha-\mathrm{Al}_{2} \mathrm{O}_{3}$ (Tijburg, et al, 1991).

The time variables (leaching and calcination time) all showed a corresponding increase in yield with time until a time where further leaching resulted to significant increase in yields. The leaching and calcinations time were reaction time which only served to confirm the facts as seen in 'reaction engineering' that as reactions time increased, more product (yield) would be obtained until the reactants were completely or nearly exhausted (irreversible reactions for a batch reactor). The point at which the yields nearly became constant could be said to be that at which the maximum amount of alumina had been extracted. The leaching power of an acid increased as its concentration increased. From the chemistry of the reactions, it was expected that the diffusion rates of $\mathrm{Al}^{3+}$ ions from the solid state to the solution increased as the concentrations and diffusion of hydronium ions increased. A maximum was reached between the concentrations of $4 \mathrm{M}$ and $8 \mathrm{M}$ acid, after which the yields decreased. This may be either due to the kaolin structure of the clay collapsing or due to the increased presence of $\mathrm{Al}^{3+}$ ions blocking the diffusion of the $\mathrm{H}^{+}$ions of the acid. It is well-known that decrease in the particle size of reactants increased the surface area available for reactions and thus increased reactions rates and yields within a given period. This was evident from the experiments as there was increase in the yields of alumina when particle size was reduced to 75 and $150 \mu \mathrm{m}$.

Table 3: Maximum percent yield using nitric acid and acetic acid

\begin{tabular}{lccccc}
\hline Process Variables & $\mathbf{X}_{\mathbf{1}}$ & $\mathbf{X}_{\mathbf{2}}$ & $\mathbf{X}_{\mathbf{3}}$ & $\mathbf{X}_{\mathbf{4}}$ & $\mathbf{X}_{\mathbf{5}}$ \\
\hline Awgbu Clay and Nitric Acid & 18.00 & 59.04 & 59.74 & 32.16 & 36.05 \\
Awgbu Clay and Acetic Acid & 16.30 & 46.55 & 46.57 & 24.30 & 15.56 \\
Akpugo Clay and Nitric Acid & 30.05 & 53.47 & 54.86 & 41.70 & 37.97 \\
Akpugo Clay and Acetic Aicd & 18.11 & 43.23 & 43.23 & 26.73 & 24.89 \\
Enito II Clay and Nitric Acid & 49.47 & 56.50 & 51.59 & 40.69 & 52.03 \\
Enito II Clay and Acetic Acid & 49.88 & 43.41 & 41.34 & 20.33 & 39.84 \\
Ikot-Abasi Clay and Nitric Acid & 46.46 & 68.10 & 63.63 & 48.17 & 58.70 \\
Ikot-Abasi Clay and Acetic Acid & 23.89 & 38.07 & 33.89 & 33.38 & 38.01 \\
\hline
\end{tabular}

In summary, Table 3 shows the maximum yield of alumina attained for each process variables using nitric and acetic acids respectively: The constant values of the variables used while varying other variables of interest such as: Calcination temperature, $600^{\circ} \mathrm{C}$; Calcination Time, 1 hour; Leaching time, 80 minutes; Acid concentration, $6 \mathrm{M}$; and Particle size, $150 \mu \mathrm{m}$. These were the optimal values of operating variables as compared with literature.

\section{Conclusion}

Locally sourced clays from four locations in Nigeria have been treated, leached and characterized to produce alumina. From the leaching experiments performed, it was obvious that the most influencing factor that affects alumina leaching of local clays using nitric and acetic acid was the calcination temperature. This factor was responsible for the highest yield obtained during the leaching process. The optimum operating conditions of $150 \mu \mathrm{m}$ particle size, calcination period of 1 hour, leaching time of between 60 to 80 minutes and calcination temperature between $400^{\circ} \mathrm{C}$ and $800^{\circ} \mathrm{C}$, the yields of alumina for each of the clays were as follows: Ikot-Abasi clay + nitric acid and Ikot-Abasi clay + acetic acid $-68.10 \%$ and $38.07 \%$ respectively, Enito II clay + nitric acid and Enito II clay + acetic acid $-56.50 \%$ and $43.41 \%$ respectively, Awgbu clay + nitric acid and Awgbu clay + acetic acid $59.04 \%$ and $46.55 \%$ respectively and Akpugo clay + nitric acid and Akpugo clay + acetic acid $-53.47 \%$ and $43.23 \%$ respectively

\section{References}

Abali, Y., Copur, M. and Yavuz, M. (2006). Determination of the Optimum Conditions for Dissolution of Magnesite with $\mathrm{H}_{2} \mathrm{SO}_{4}$ Solutions, Indian Journal of Chemical Technology, 13, 391-397.

Ajemba, R.O. and Onukwuli, O.D. (2012). Studies of the Effects of Hydrochloric Acid-Leaching on the Structural and Adsorptive Performance of Nteje (Nigeria) Clay, International Journal of Engineering Research and Technology (IJERT), 1(3), 1-11.

Ajemba, R.O. and Onukwuli, O.D. (2012). Process Optimizaton of Sulphuric Acid Leaching of Alumina from Nteje Clay Using Central Composite Rotatable Design, International Journal of Multidisciplinary Sciences and Engineering, 3(5), 1-7.

Al-Ajeel, A.A. and Al-Sindy, S.I. (2006). Alumina Recovery from Iraqi Kaolinitic Clay by Hydrochloric Acid Route, Iraqi Bulletin of Geology and Mininig, 2(1), 67-76.

Al-Zahrani, A.A. and Abdul-Majid, M.H. (2009). Extraction of Alumina from Local Clays by Hydrochloric Acid Process, Journal of King Abdulaziz University (JKAU), 20(2), 29-41.

Aramide, F.O., Alaneme, K.K., Olubambi, P.A. and Borode, J.O. (2014). Characterization of Some Clay Deposit in South West Nigeria, Leonardo Electronic Journal of Practices and Technology, 25, 46-57. 
Austin, G. (1984). Shreve's Chemical Process Industries, McGraw-Hill, New York, 244-250, 355-359.

Bakr, M.Y. and El-Abd, M.A. (1969). Extraction of Alumina from Egyptian Kaolins and Clays: Part IV - Alumina Extraction by the Hydrochloric Acid Method, Indian Journal of Technology, 7, 405-409.

Box, G.E., Hunter, J.S. and Huner, W.G. (2005). Statistics for Experimenters: Design, Innovation and Discovery, John Wiley and Sons, New Jersey, USA, 173-233.

Fakolujo, O.S., Olokode, O.S., Aiyedun, P.O, Oyeleke, Y.T, Anyanwu, B.U. and Lee, W.E. (2012). Studies on the Five Selected Clays in Abeokuta, Nigeria, The Pacific Journal of Science and Technology, 13(1), 83-90.

Geankoplis, C.J. (2006). Transport Processes and Separation Process Principles, Prentice-Hall of India, New Delhi, India, 802-803.

Guggenheim, S. and Martin, R.T. (1995). Definition of Clay and Clay Mineral: Joint Report of the AIPEA Nomenclature and CMS Nomenclature Committees, Clay and Clay Minerals, 43(2), 255-256.

Kenny, J.B. (1976). The Complete Book of Pottery Making, Isaac Pitman and Sons, London.

Kirk-Othmar. (1998). Encyclopedia of Chemical Technology, Volume 1: A to Alkaloids, USA, John Wiley and Sons, USA, 63-64, 251-269.

Kirk-Othmar. (1998). Encyclopedia of Chemical Technology, Volume 2: Alkanolamines to Antibiotics, John Wiley and Sons, USA, 130-153.

Liu, Y., Zheng, Y. and Wang, A. (2010). Response Surface Methodology for Optimizing Adsorption Process Parameters for Methylene Blue Removal by a Hydrogel Composite, Adsorption Science and Technology, 28, 913-921.

Lori, J.A., Lawal, A.O. and Ekanem, E.J. (2007). Characterization and Optimization of Deferration of Kankara Clay, ARPN Journal of Engineering and Applied Sciences, 2(5), 60-74.

Manukaji, J.U. (2013). Industrial Potential of Some Clay Deposits in Kogi State North Central Nigeria, American Journal of Engineering Research (AJER), 2(4), 33-38.

Mark, U. (2010). Characterization of Ibere and Oboro Clay Deposits in Abia State, Nigeria for Refactory Applications, International Journal of Natural and Applied Sciences, 6(3), 296-305.

Matthews, P. (2003). Advanced Chemistry, Cambridge University Press, London.

Obaje, S.O., Omada, J.I. and Dambatta, U.A. (2013). Clays and their Indutrial Applications: Synoptic Review, International Journal of Science and Technology, 3(5), 264-270.

Olaremu, A.G. (2015). Sequential Leaching for Production of Alumina from a Nigerian Clay, International Journal of Engineering Technology, Management and Applied Sciences, 3(7), 103-109.

Osabor, V.N., Okafor, P.C., Ibe, K.A. and Ayi, A.A. (2009). Characterization of Clays in Odukpani, South Eastern Nigeria, African Journal of Pure and Applied Chemistry, 3(5), 79-85.

Ozdemir, M. and Cerisli, H. (2005). Extraction Kinetics of Alunite in Sulfuric Acid and Hydrochloric Acid, Hydrometallurgy, 76, 217-224.

Rastall, R.H. (1916). Agricultural Geology, Cambridge University Press, London, 88-89.

Uchenna, U., Onukwuli, O.D., Ajemba, R. and Ude, C.N. (2015). Kinetics Studies of Hydrochloric Acid Leaching of Alumina from Agbaja Clay, International Journal of Research in Advanced Engineering and Technology, $1(1), 64-72$. 